John C. Weicher is a senior fellow at the Hudson Institute and was a visiting scholar at the Federal Reserve Bank of St. Lovis. Heid L Beyer provided research assistence.

\section{Changes in the Distribution of Wealth: Increasing Inequality?}

\section{John C. Weicher}

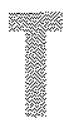
his article describes the changes in the distribution of wealth among U.S. households that occurred between 1983 and 1989 , and analyzes the role of several demographic and economic factors in contributing to the changes. It makes use of the Federal Reserve Board's Survey of Consumer Finances, which is one of the few sources of time-series information on household wealth that reports asset holdings of individual households for a sample of the entire population. The period from 1983 to 1989 is a convenient and useful period to study, because it corresponds approximately to a single economic period: the economic expansion that began in November 1982 and ended in June 1990. Academic and popular interest in distributional issues has increased in recent years, and the 1980 s have attracted particular attention in the popular press, although most of the attention has been given to changes in the distributions of income and wages

The article frst describes the data in some detail and then the measures of inequality. The third section reports changes in wealth holdings for U.S. households, cross-classified in several ways. This is followed by analysis of the changes in the distribution of wealth, including investigation of some possible explanations for the changes. The final section describes the wealth holdings of the richest 1 percent of U.S. households, who have a large share of total household wealth and whose holdings have been given special attention in previous research.

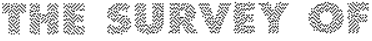

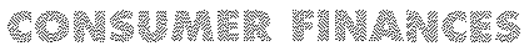

The Survey of Consumer Finances is conducted by the Survey Research Center of the University of Michigan for the Federal Reserve Board. It was taken at six-to-eight-year intervals between 1962 and 1983, and at three-year intervals since then. The most recent avalable surveys that are also useful for analysis of the distribution of wealth are those for 1983 and 1989! These surveys are partly longitudinal; some households were interviewed in both years, but they are not identified on the 1989 public-use tape.

In both of these years, the survey has two samples. The larger is a cross-section chosen randomly to tepresent the entire population of households. It consists of 3,665 households in 1983 and $2,277 \mathrm{in} \mathrm{1989.} \mathrm{The} \mathrm{smaller} \mathrm{is} \mathrm{a}$ "high-income" sample of households expected to have unusually large wealth holdings. Because the wealthiest I percent of households hold over a quarter of total household wealth, a national sample of households witl therefore give litte information about a large fraction of household wealth. The additional high-income sample was intended to overcome this limitation. It was selected from IRS records. Households selected were first asked if they would participate in the survey, and then interviewed if they were willing. Procedures were followed to insure confidentiality; the IRS did not know which households participated. There were 438 households in the high-income sample in 1983 and 866 in 1989

The surveys are very similar but not identical. The 1983 survey, for example, reports calculations of the present value of Social Security benefits and private pensions expected by workers who are at least 40 years old and have not yet retired. These calculations are based on assumptions about future labor force participation, wages and inflation,
1 The 1986 sunvey consisted of tellephone retinterviews of 2,822 housentads from the $1993 \mathrm{SCF}$, with much less defdal on asset holdings. The 1992 servey datu tope is fot yet publicly availdale, wet Kennickell ond Star-Holluer (1994) teport preliminan findings and a comperison with 1989.

${ }^{2}$ Anvother 159 housetwilds were interviewed in 1983 os pot of the notiontal trass-5ection, but are excluded from this andiysis as from the Federal Reserve Boord's "deaned somple," hecause of norresponse. See Avery and Elilehrusen $(1990,0 p, 1678)$ 


\section{Measuring Long-Term Trends in Wealth}

Weal th is the value of assets accumulated over long periods, and changes in total wealth and its distribution over short periods of a few years provide incomplete information about individual well-being. The Surveys of Consumer Finances provide the best recent information for different points in time, but it is still difficult to analyze long-term changes in the distribution of wealth with these surveys. The only previous Federal Reserve survey with a comparable sample, including high-wealth households, is the 1962 Survey of the Financial Characteristics of Consumers (SFCC). Wolff $(1987,1994)$ has compared the 1962 and 1983 data and finds little change in the distribution over that period as a whole for measures of wealth that include owner-occupied housing, but an increase in concentration for narrower measures limited to financial assets.

The 1977 survey has much less information on wealth holdings than the later surveys. It primarily reports on the credit experience of households, and is in fact entitled the Survey of Consumer Credit (SCC) rather than the Survey of Consumer Finances. It does not include all wealth categories, omitting some that are important, such as holdings of unincorporated or closely held businesses. The wealth holdings in each category are reported in brackets, with a top bracket of $\$ 200,000$ or more, while the later surveys report holdings to the dollar. It is therefore difficult to compare 1977 with the later years. (Analysis of the $1983 \mathrm{SCF}$ shows that the results are quite sensitive to whether the data are bracketed and what convention is used for the top bracket.) Also, the period between 1977 and 1983 includes two very different economic experiences: three years of accelerating inflation and economic expansion between 1977 and 1980, followed abruptly by back-to-back recessions and unanticipated disinflation during the early $1980 \mathrm{~s}$.

These limitations are worth mentioning because comparisons of the 1977 and 1983 surveys attracted substantial press attention when the data from the 1983 SCF were first available; a comparison published by the Joint Economic Committee appeared to show a dramatic increase in concentration. The increase turned out to be due to an apparent error in reporting the holdings of one wealthy household (Curtin, Juster and Morgan, 1989, discuss this and other individual observations with questionable responses). The more fundamental problems with comparisons are the differences in coverage of wealth and reporting procedures between the two surveys.

${ }^{3}$ For more extersive descriptions of Hhese surveys, see Avery ond others (19840), Avery and Elliehtiousetit (1986), Avery, Glitehausen and Rennickell (1988), Kentiicket and Shack-Marquez (1992) and Kenteckell and Woodbun (1992). among other factors. The 1989 survey does not contain these calculations; it reports only the payment amount of a private pension. For 1983, locational information has been made available on the metropolitan area or county level for the cross-section sample (not the high-income sample), while for 1989 no geographic information has yet been provided on the data tape, although it was collected. Regional information will be released for 1989 in the future. Geographic information would obviously be useful for analyzing some components of wealth, notably real estate. ${ }^{3}$

With a survey design combining a random sample of all U.S. households and a separate sample of the top few percent of the wealth distribution, it becomes important to weight the individual observations appropriately so that the sample households adequately represent the universe of all households. Analysts at both the Survey Research Center and the Board have devoted substantial attention to the issue of weighting. Both surveys include weights for individual households on the basis of the national cross-section sample and the combined sample. The choice of weights can affect the results, as will be seen later in this article.

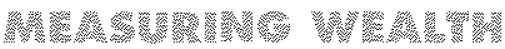

Wealth is defined as the value of assets minus the value of liabilities. The SCF contains detailed, though not quite exhaustive, 
information on both assets and liabilities, most of which is used in this analysis. The data in the surveys also pose some problems for analysts, particularly with respect to comparison with other surveys and the process of weighting the sample observations to represent the nation as a whole.

\section{Arentable Dofe he we ser}

Assets reported in the SCF include both financial and real assets. Financial assets consist of household holdings at depository insitutions in the form of checking accounts, savings accounts, money market accounts and certificates of deposit; holdings of publicly traded corporate stock, bonds of various kinds, including government bonds, U.S. savings bonds, corporate, mumicipal and foreign bonds; holdings of mutual funds; retitement accounts, such as IRAs and Keoghs; trusts; the cash value of life insurance policies; the current value of thrift-type pensions; and debts owed to the household.

As noted previously, the SCF also provides information on other private pensions that the household expects to receive in the future and (in 1983 only) Social Security benefits, even though the household cannot convert them to cash.

Real assets include: owner-occupied housing; other real estate, such as aparment buildings and office and commercial buildings; unincomporated, closely held businesses; automobiles; boats and airplanes; and collectibles such as coins, stamps or objets dart.

The surveys do not inclucte constmer durables besides automobiles and other vehicles, although the debt incurred to buy consumer durables is teported as a liability. The rationale for this is that consumer durables are generally held for use, not as a store of wealth. Estimating the value of consumer durables is also difficult. Nonetheless, they do constitute part of the possessions of households, perhaps a substantial part for lower-income households. They can be taken into account either by attempting to estimate their value (a procedure followed by Wolff, 1987), or by excluding the debt incurred to buy them as well as their value on the ground that the total value of al consumer durables is likely to be at least as large as the remaining debt on them, for most households. The latter is the simpler procedure.

Automobiles appear to be in an intermediate category. They are probably not held as a store of value, but they can be converted to cash much more easily than other consumer durables.

Liabilities consist of home mortgage debt, including: home equity lines of credit; debt on other real estate; lines of credit other than home equity loans; outstanding credit card debt; amounts owed on automobile loans; money owed to a business owned by the household; money borrowed against life insurance or other savings or retirement plans; and money owed to a cash or call money brokerage account.

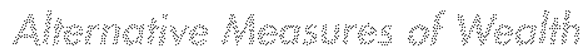

It is possible to construct several different definitions of wealth from the SCF, and analysts have done so. In this article, the basic definition includes all of the assets and liabilities in the SCF except the present value of pensions now being received and expected, which is reported in full only for 1983. The difference between these assets and liabilities will be referred to as "net worth" or "wealth" without further qualification. This definition is the same as that used by Kennickell and Shack-Marcuez (1992), except that they exclude miscellaneous assets (mainly collectibles) in 1983 but not 1989.5 It differs from Wolfs (1994) preferred measure, termed "net worth," in two ways: Wolff excludes miscellaneous assets and the value of automobiles (but includes atutonobile loans). Wolff also reports a measure that includes the value of automobiles, termed "net worth plus antos," which is closer to the preferred measure in this article, and "financial net worth" (excluding both the value and the mortgage on owneroccupied housing as well as automobiles from net worth).

Other analyses have used both broader and narrower measures, which complicates comparisons between studies. Wolff (1987) includes miscellaneous assets for 1983, and reports five measures, ranging from an inclu-
Tom:e rest debt are reporten also.

"Huery ond Elliehousen (1990) wars is the cockethok for 1983 that "some estimnies [for miscceilat neous assets? lod so be vey dubjous." Irotuding or exdudtug mis-

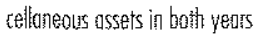
toes not chonge the resutts in this anticle. 
sive concept that adds an imputed value for other consumer durables and household inventories to the assets in the SCF, to "capital wealth," which is limited to currency, deposits in financial institutions, money market funds, and pension and insurance cash surrender value. Avery, Elliehausen and Canner (1984b) report net worth for 1983, and also 1977 , excluding automobiles, the cash value of life insurance, the present value of expected future pension benefits, and equity in small businesses and farms (which were not repotted in the $1977 \mathrm{SCO}$.

\section{Werghonger}

With a survey design combining a cross-section sample of all U.S. households and a separate sample concentrated in the top few percent of the wealth distribution, it becomes important to weight the individual observations appropriately so that the sample households adequately represent the universe of all households. Analysts at both the Board and the Survey Research Center have devoted substantial attention to the issue of weighting, and have developed alternative weights, which are commonly referred to as FRB and SRC weights, respectively. In 1983, the FRB and SRC weights differed primarily in the way that they combined separate weights for the cross-section and the high-income samples. After the initial weights were developed, a second set of FRB weights was constructed when 1982 individual income tax data suggested that the high-income sample may have been given too much weight. These are known as the "FRB extended-income" weights."

Alternative weights have also been constructed along a second dimension: whether the sample was "blown up" to the U.S. total on the basis of the 1980 decennial Census or the 1983 Current Population Survey (CPS). Most recent studies have used 1983 CPS weights, but these were not available on data tapes until after 1985; both Avery and others (1984a, 1984b) and Wolf (1987) used 1980 decennial Census weights.

In this article, the FRB extended-income weight and the latest SRC weight (the revised SRC composite weight) are used for 1983. (These are variables $\mathrm{B} 3016$ and $\mathrm{B} 3019$, respectively, on the data tape.) Kennickell and Shack-Marquez (1992) use the FRB extended-income weight.

For 1989, two SRC weights are available: a preliminary weight used by Kennickell and Shack-Marquez (1992) for comparing 1983 to 1989 , and a final weight used by Kennickell and Starr-McCluer for comparing 1989 to 1992 (variables X40125 and X40131). Both are closer in design to the 1983 FRB weight than to the SRC weight. An experimental FRB weight (variable X40202) was included in early versions of the public-use tape, but dropped from those currently available. Wolff (1994) reports that it generates wealth. totals that are less consistent with the Flow of Funds (FOF) than the SRC weights. (This issue is discussed further in the next section.) Both SRC weights are used in this article. The choice of weights can affect the results, as will be seen later.

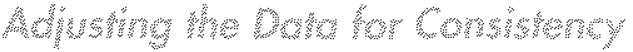 Wh Ohas boures}

The total asset and liability values in the SCF differ from information in other sources in both 1983 and 1989. In particular, there are substantial differences between the SCF and the FOF, published by the Federal Reserve Board, which reports aggregate data over time on the composition of national wealth. In several categories, the SCF total is much smaller. There appears to be general agreement that the SCF is a better source for the current values of owner-occupied housing and unincorporated businesses, but differing views on the relative accuracy of the data for financial assets and liabilities. The conceptual differences in coverage are analyzed most extensively by Avery, Elliehausen and Kennickell (1988) with reference to 1983 , and by Antoniewicz (1994) for 1989 and 1992. Wolff $(1987,1994)$ also discusses the differences and compares them for both years.

Analysts have teached different conclusions about the relative merits of the two surveys and followed different procedures in adjusting for these discrepancies. Wolff $(1987,1994)$ takes the FOF as the more accurate source for financial asset values and adjusts many of the SCF figures for individual 
households by the ratio of the aggregate totals for the SCF and the FOF. Avery, Elliehausen and Kennickell (1988), Avery (1989) and Curtin, Juster and Morgan (1989) have argued that the SCF is more likely to be accurate for 1983 than the FOF in most instances. They conclude that total assets and liabilities in most categories are similar when the data are reported on the same conceptual basis. Avery (1989) points out that the FOF figures for households are computed as balancing residuals, and thus are sensitive to measurement errors for every other sector. He also notes that totals for broad categories of assets, such as bonds, are often closer than for sub-categories such as federal bonds or municipal bonds, and suggests this may result from misclassification.

If holdings of the sub-categories are not uniform across the wealth distribution, adjustment may distort the measured degree of inequality. Neither Avery and others (1984a, 1984b), Avery and Elliehausen (1986) nor Kennickell and Shack-Marquez (1992) adjust the SCF data. Smolensky (1989) reviews the issue for the 1983 data and concludes that the SCF is likely to be the better data source, partly on the general grounds that cross-section surveys usually employ state-of-the-art methodology, while time-series data collection and processing change slowly for an ongoing series, for good reason but perhaps at the cost of failing to capture changes in the economy.

Several basic differences between the SCF and FOF apply to all asset categories. The FOF "household" sector includes nonprofit institutions and personal trusts as well as households. Wolff uses a 1980 estimate for households alone, relative to the FOF for that year, to adjust the FOF for 1983 (and apparently also for 1989). Avery, Elliehausen and Kennickell use Federal Reserve Board estimates of the "real" households within the FOF sector to adjust the FOF totals. In addition, the data refer to slightly different periods. The SCF was conducted early in 1983 . Wolff uses the average of 1982 and 1983 year-end tolals from the FOF as the basis of comparison, while Avery, Elliehausen and Kennickell use the end of 1982 . Since 1983 was a year of economic recovery, in which stock and bond prices rose by 20 to 30 percent, Wolffs method results in larger FOF values and a bigger difference.

Analysts also differ in their calculated SCF totals for individual asset and liability categories because they have used different weights. Wolff (1987) uses weights for the 1980 decennial Census, which blow up the sample to 79.8 million households, while Avery, Elliehausen and Kennickell use weights based on the 1983 CPS, which blow up the sample to 83.9 million households. In most cases, Avery, Elliehausen and Kennickell report a larger total for the $\mathrm{SCF}$, and therefore a larger $S \mathrm{CF} / F O F$ ratio. Some of the differences are substantial: Wolff calculates mortgage debt at $\$ 704$ billion, or 63 percent of the FOF total, for example, while Avery, Elliehausen and Kennickell calculate it at $\$ 975$ billion, or 92 percent. In this article, the 1983-based weights are used and the calculated SCF totals are usually closer to Avery, Elliehausen and Kennickell than to Wolff.

The larger discrepancies occur on the liability side in both years. They are so large that adjusting individual household data for the difference between the SCF and FOF leads to some rather odd results, especially for households which report large consumer debt. Adjusted wealth for these households is sometimes large and negative, while unadjusted wealth is large and positive. In 1983 . for example, the 10 poorest households on an adjusted basis included five with wealth over $\$ 1$ million on an unadjusted basis; one household went from $+\$ 4.3$ million to $-\$ 9.3$ million. When assets and liabilities are adjusted, 17 percent of all households in 1983 and 13 percent in 1989 reported negative net worth. Wolff (1994) suggests that the differences in liabilities between the SCF and FOF probably occur because of failure to report a debt, rather than understatement by households which do report it; in that case, proportional adjustment is likely to misrepresent the position of households which actually report relatively large debt holdings to begin with. In his analysis of the $1989 \mathrm{SCF}$, he therefore adjusts assets, but not liabilities, to be consistent with the FOF. Given the much smaller SCF/FOF debt ratios for 1983, the same argument would appear to hold for that year as well. 
Mean Household Wealth, 1983 and 1989

(in thousands of 1989 dollars)

\begin{tabular}{|c|c|c|c|c|}
\hline & $\begin{array}{l}\text { T983 FRB } \\
(B 3016)\end{array}$ & $\begin{array}{l}1983 \text { SRC } \\
(\mathrm{B} 3019)\end{array}$ & $\begin{array}{l}1989 \text { SRC } \\
(\times 40131)\end{array}$ & $\begin{array}{l}1989 \text { SRC } \\
(\times 40125)\end{array}$ \\
\hline \multicolumn{5}{|l|}{ Uniadiusted: } \\
\hline Intuding outos & $\$ 150.9$ & $\$ 160.5$ & $\$ 184.7$ & $\$ 180.7$ \\
\hline Exduding ow os & 145.9 & 155.0 & 176.6 & 172.6 \\
\hline Extuding sutos and homes & 102.8 & 1128 & 126.7 & 121.3 \\
\hline 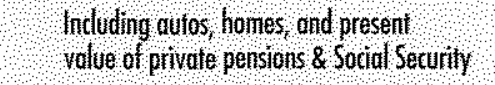 & 222.3 & 231.8 & $\mathrm{NA}$ & $\mathrm{NA}$ \\
\hline \multicolumn{5}{|l|}{ Adjusted (essets and liabiifites): } \\
\hline Intuding outos & $\$ 1658$ & $\$ 173.4$ & $\$ 200.4$ & $\$ 194.7$ \\
\hline Exeluding autos & 160.4 & 167.9 & 192.3 & 186.6 \\
\hline Exeluiding autos cad homes & 125.2 & 1333 & 142.4 & 135.3 \\
\hline Inttuding autos, lomes, and peesent & 237.2 & 244.7 & HA & $\mathrm{NA}$ \\
\hline \multicolumn{5}{|l|}{ yolue of private pensions \& Socid Security } \\
\hline \multicolumn{5}{|l|}{ Adfusted (ossess only) } \\
\hline Intuding outos & $\$ 1878$ & $\$ 196.9$ & $\$ 207.7$ & $\$ 201.8$ \\
\hline Exeloding outos & 1823 & 191.4 & 199.5 & 193.7 \\
\hline Exluding oufsos ond hones & 139.7 & 149.2 & 149.6 & 1424 \\
\hline Ancone. & $\$ 334$ & $\$ 350$ & $\$ 38.8$ & $\$ 35.8$ \\
\hline \multicolumn{5}{|l|}{ 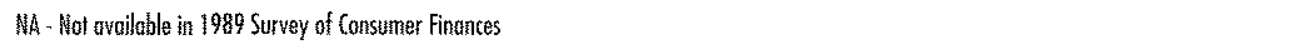 } \\
\hline \multicolumn{5}{|c|}{ HOTE: 1983 volues odjusted to 1989 using the CPI-1I annud average for the calandar yours (1983 values multiplied by 1.24498 ). } \\
\hline \multicolumn{5}{|c|}{ 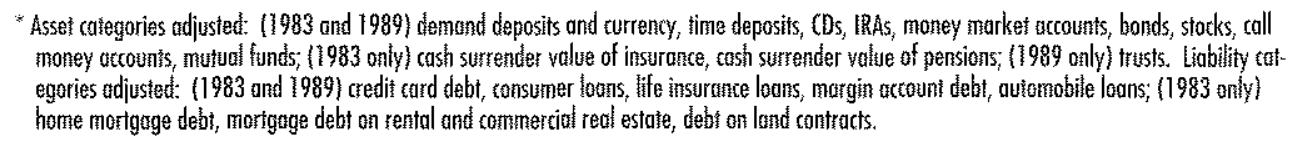 } \\
\hline \multicolumn{5}{|l|}{ SouRCE: Survey of Capsumet Finates, 1983 and 1989} \\
\hline
\end{tabular}

On balance, it seems best not to adjust the data, because the 1983-based weights are used and also because adjusting liabilities affects the individual household data so greatly. This article therefore uses unadjusted data for most of the analysis, but also reports results with Wolfes adjustments on both sides of the balance sheet (his 1983 procedure) and with. assets adjusted but liabilities not adjusted (nis 1989 procedure).

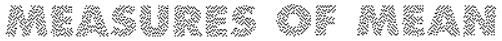 W}

Table 1 reports mean household wealth for 1983 and 1989. The first panel uses unadjusted data for both sets of weights in each year. On any comparison, mean wealth increased between 1983 and 1989 , but the magnitude depends on the weights chosen. The increase ranges from $\$ 20,000$ to $\$ 34,000$ The choice of weights is particularly important for 1983; the difference in mean wealth is atmost $\$ 10,000$. During the six years, mean. household wealth increased by 13 percent to 22 percent. The first and last columns show weath for the weights used by Kennickell and Shack-Marquez (1992). The increase was 20 percent on the basis of these weights.

The table shows the importance of: owner-occupied housing and the present value of future pension benefits. Future pen- 
sions were close to one-third of mean household wealth in 1983, and owner-occupied housing constituted about 30 percent of the remainder in both years, more than any other asset. Automobiles wete the most widely held asset ( 84 percent of all households in both years). Among financial assets, corporate stocks comprised the largest share (19 percent in both years), and checking accounts were the most widely held ( 79 percent of all households in 1983 and 75 percent in 1989). On the liability side, credit card debt was the most common fortn of debt in both years, but home mortgages were almost equally frequent. Home mortgage debt accounted for over half of all family debt in both years.

The lower panels show the effect of adjusting assets and liabilities. Adjustment adds $\$ 36,000$ to $\$ 37,000$ to assets and $\$ 22,000$ to $\$ 23,500$ to liabilities in 1983 . It is less important in 1989, however, adding $\$ 21,000$ to $\$ 23,000$ to assets and $\$ 7,000$ to liabilities. Using the adjusted data, increases in mean household wealth are smaller in both percentages and amounts. Home equity accounts for about one-third of the increase in the unadjusted data $(\$ 7,000$ to $\$ 9,000)$, but over half $(\$ 15,000$ to $\$ 17,000)$ when both assets and liabilities are adjusted.

The table also shows mean household income, which is a pre-tax figure reported by the respondent. The SCF asks about total income and also income from various sources. In many cases, the sum of the latter does not equal the total.

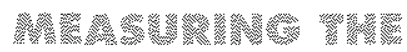

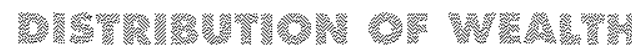

Two types of measures of distribution are commonly used in economics: measures describing the entire distribution and measures describing the extent of concentration at one end of it.

The most common examples of the first type are the Lorenz curve and its companion. the Gini coefficient, which are often used to measure the distribution of income. The distribution of wealth is usually measured by a concentration ratio, such as the share of total wealth held by the richest 5 percent or 1 percent of all households, because it is so highly skewed. Concentration ratios have also been popular because one of the few time-series measures of wealth is the estate multiplier, which is a method of estumating the wealth of the richest households from estate tax returns, which are filed mainly by well-to-do individuals, and mortality tables to estimate the holdings of well-to-do living households.

The SCF provides information not only about wealthy households but also about the broad middle class and the poor ${ }^{\text {i0 }}$ The Lorenz curve and the Gini coefficient can be used to describe the distribution of wealth among all households in the SCF in exactly the same way as they are used to measure the distribution of income in household surveys.

A schematic Lorenz curve is shown in Figure 1. It depicts the total number of households on the horizontal axis and their total wealth holdings on the vertical axis. To construct the Lorenz curve, households are first arrayed in ascending order by wealth. Then the cumulative total wealth is calculated, beginning with the poorest household and ending with the richest one. These values are plotted for each household on the diagram, and then connected to construct the curve. Thus, for example, the first point on a Lorenz curve might represent one household with wealth of $\$ 10$, the second point might represent two households with total wealth of $\$ 21$, and so on. Any given point on the curve shows that the poorest $x$ percent of households own $y$ percent of all wealth in the society.

Two limiting cases are easily shown and may clarify the concept. If the distribution of wealth is perfectly equal, then every household has the same amount of wealth, and the Lotenz curve is the diagonal line running from the origin at the lower left at a 45-degree angle to the point in the upper right corner of the diagram representing the total number of households and their total wealth. At the opposite extreme, if all wealth belongs to one household, then the Lorenz curve lies along the horizontal axis until it reaches the point tepresenting the total number of households; the Lorenz curve then becomes the vertical line on the right side of the diagram.

The Gini coefficient is calculated from the Lorenz curve as the ratio of the area between the diagonal and the Lorenz curve over the
${ }^{15}$ Avey, Fllighousen and Keftinckell (1987) compore estote tax dato with the SCF for 1983. 


\section{Und}

\section{Lorenz Curve and Gini Coefficient}

\section{Percent of aggregate wealth}

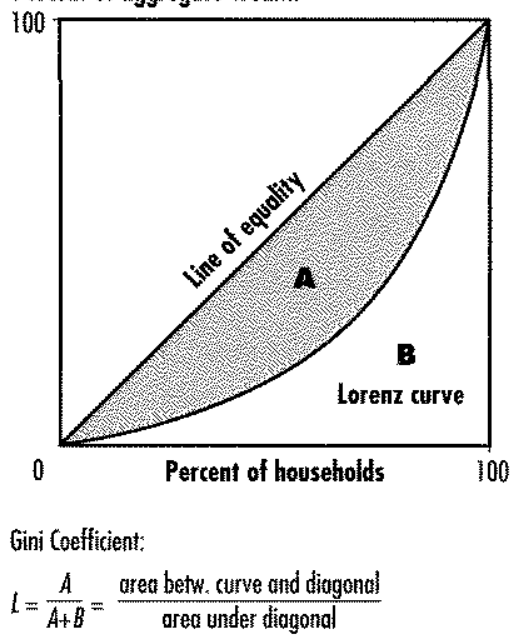

area under the diagonal, or $L=A /(A+B)$. The Gini coefficient is therefore bounded by zero and 1. If the distribution of wealth is perfectly equal, the Lorenz curve lies along the diagonal, the value of $A$ is zero, and the Gini coefficient line segments, with the length of each segment is zero. If one household owns all the wealth, the area under the Lorenz curve is the same as the area between the diagonal and the $x$-axis, the ratio is 1.0 and the Gini coefficient is unity. The greater the concentration of wealth, the closer the Gini coefficient is to unity.

With weighted or bracketed data, the Lorenz curve consists of a series of straightbeing the weight of the observation. The 1983 and 1989 SCF contain more than 4,000 and more than 3,000 observations, respectively, so the line segments approximate closely to a curve and the area $B$ approximates to the integral of the Lorenz curve. The Gin coefficients reported in this article are calculated from the line segments. The area $A$ is the sum of the areas above the line segments and below the diagonals.

\footnotetext{
7 from and Tibshineri (1993) is an excellent interodection to the heo SeF sample is nol random does alo iss as the artul estimut (plas noise?, so the brotstron piocedure troces out the behavior of the actual sampling arocedure. For on atternative procedue using the (1991), who prowided o EORTRAN progrom that served as a siouting point for the and alysis. Also, see Lemos and Yithaki (1989).
12 Whafef (7994) efers to an incrense of. OA in the Gini coefficient between 1983 and 1989 as "shore," and a difference of .02 between Gini coeffecients for wo different mensures of weath in 1989 as "fot great." He does not report Gini coefficients to mone thon two ploces.

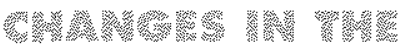

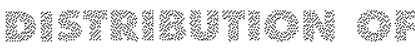

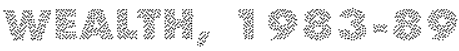

Table 2 reports Gini coefficients for 1983 and 1989 , in a parallel form to Table 1 . The data in the table demonstrate the importance. of the technical issues discussed in the preceding section and suggest several broad conclusions.

\section{The importunce of Waighfory}

The determination of whether there has been an increase in inequality depends on the choice of weights. For the broadest measure of wealth, and using unadjusted data, the change from 1983 to 1989 varies from -0.002 to +0.027 . The Gini coefficients differ by 0.017 for the two sets of weights in 1983 , and by $0.012 \mathrm{in} 1989$. The standard errors of these Gini coefficients, skown in italics in Table 2, are large enough to cast doubt on whether there was an increase in inequality over the period. To analyze the significance of the difference in the Gini coefficients, bootstrap estimates of standard errors were calculated using 1,000 replications." The difference between the 1989 and $1983 \mathrm{Gini}$ coefficients was positive in 920 cases when B3016 and X40125 were used as weights, and in 992 cases when B3016 and X40131 were used. However, it was positive in only 479 cases when B3019 and X40125 were used, and in 785 cases when $B 3019$ and X40131 were used. Finally, the weights for each year were averaged (a technique used by Wolff, 1994, for the 1989 survey); in this instance, the difference was positive in 873 cases. These results indicate that the increase in tnequality was more or less on the margin of significance. Whether the magnitude of the difference is politically or socially important is a matter for individual judgment. ${ }^{12}$

By most of the other measures reported in Table 2, the distribution of wealth became somewhat more unequal over the period. When first automobiles and then owneroccupied housing are excluded, all of the 1983-1989 comparisons show an increase in inequality, but the choice of weights still affects the extent of the increase.

In the remainder of this article, comparisons will be based on the weights used by Kennickell and Shack-Marquez (1992), unless otherwise indicated. These are variables $B 3016$ and $X 40125$. 


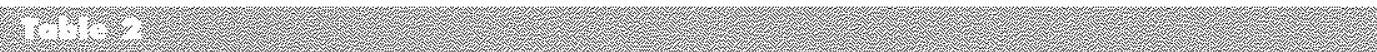

Gini Coefficients, 1983 and 1989

(allernative weights)

\begin{tabular}{|c|c|c|c|c|}
\hline & $\begin{array}{l}1983 \text { FRB } \\
(B 3016)\end{array}$ & $\begin{array}{l}1983 \text { SRC } \\
\text { (B3019) }\end{array}$ & $\begin{array}{l}1989 \text { SRC } \\
(\times 40131)\end{array}$ & $\begin{array}{l}1989 \text { SRC } \\
(\times 40125)\end{array}$ \\
\hline \multicolumn{5}{|l|}{ Unadivsted: } \\
\hline Including outos & .778 & 795 & .805 & .793 \\
\hline Stondord enos & .008 & .009 & .008 & .008 \\
\hline Exduding aufos & 798 & .814 & .826 & .815 \\
\hline Extluding autos ond lomes & .900 & .912 & .925 & .921 \\
\hline $\begin{array}{l}\text { Indluding outos, homes, ord present } \\
\text { Volue of privute pensions \& Soci }\end{array}$ & 690 & 708 & N.A. & NA. \\
\hline \multicolumn{5}{|l|}{ Adjusted (ossets only) } \\
\hline Goduting outos & .773 & .788 & .813 & .801 \\
\hline Exaluding aufos & .788 & .803 & .832 & .821 \\
\hline Exduding autos and hones. & .865 & .877 & .920 & .915 \\
\hline \multicolumn{5}{|c|}{ Adjusted (ossets and nontmontgage debt only) } \\
\hline Inluting outos & .817 & .827 & .836 & .825 \\
\hline Excuding autos. & .836 & .846 & .858 & .848 \\
\hline Excluding autos and homes & .948 & .953 & .967 & .966 \\
\hline Incone: & .465 & .491 & .540 & .505 \\
\hline
\end{tabular}

\section{Alernalive Measures of Wouln}

The broader the definition of wealth, the more equal is its distribution, in either year. Gini coefficients are highest when automobiles, home equity and the present value of future pensions (in 1983) are excluded from wealth. They are lowest when these assets are included. Merely including automobiles in household net worth reduces the Gini coefficient by about 0.02 . Including home equity reduces it by about 0.10 , as does including the value of future pensions. These assets are widely held, as previously noted, and they clearly represent a large share of the wealth of relatively low-wealth households.

Excluding consumer debt does not have much effect on the analysis. Mean unadjusted consumer debt was $\$ 2,000$ in 1983 and $\$ 1,100$ in 1989. Gini coefficients are consistently lower when consumer debt is excluded, by 0.004 in both years. Since consumer debt is relatively more important for lower-wealth households, this is not surprising.

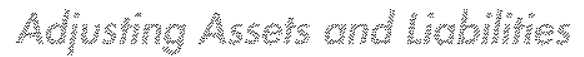

The table demonstrates the importance of adjustment, particularly on the liability side of the balance sheet. Gini coefficients are all much higher, for each set of weights and each measure of wealth, by between 0.03 and 0.05 when liabilities are adjusted. As could be expected from the fact that the adjustments are larger in 1983, the coefficients for that year are raised slightly more than the coeffcients for 1989 , and therefore the measured increase in inequality is generally smaller.

The results in Table 2 do not adjust for mortgage debt in 1983. The coefficient would be raised still further in 1983, by about a further +0.030 , if mortgage debt were also adjusted as Wolff (1987) has done, but since the SCF and FOF agree rather closely when 1983 weights are used, these results are omitted from the table.

When only assets are adjusted, the Gini coefficients are lower in 1983 and usually higher in 1989, compared to the coefficients 


\section{BEVIEW}

JANUARY/FERRUARY 1995

\section{(2)}

\section{Index Changes in Asset Value, 1983-89 (based on ennual averages, except as noted)}

\begin{tabular}{|c|}
\hline Assel Cotegory \\
\hline Stotks \\
\hline Taxabla bonds \\
\hline Tox exeepipt bondes \\
\hline Owher Ocupied houses \\
\hline Investment real estale \\
\hline Unincorporoted fossness \\
\hline Unincopposeted bussiness \\
\hline Farms \\
\hline
\end{tabular}

Index
Standard \& Poor 500
Dow-Jones 20 -bond index
Siandard \& Poor's municipal
Census ane-fanily home index
Frank Russell property index
Russell 2000
Nasdoq OTC composite index
USOA average value/acre

Percent Change, 1983-89

* Yearly tinghts

** Compiled from quanterly aver aģes; index for commertid red estate

***** last trading day in December

SOURCES: Statistical Abstroct of the United States: 1992, 1.5. Bureau of the Census, Price Index of Hew One-Fanily Homes Sold; Frank Russell (anpany; IS.S. Department of Agriculture; Lowrence I. White, The S\&L Debade, (po. $110-11)$.

based on the unadjusted data. This may reflect the fact that the largest adjustment in 1983 is for savings accounts, which are widely held, while the largest adjustment in 1989 is for stocks, bonds and trusts. The increase in inequality is about double that based on unadjusted data.

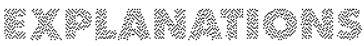

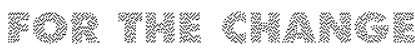

A number of phenomena have been suggested as explanations for the changes in the distribution of wealth (or income) during recent years. It is possible to examine the effects of some of these phenomena and get at least a preliminary sense of their possible importance. Three in particular are worth attention: changes in asset prices; demographic changes; and the changing distribution of income.

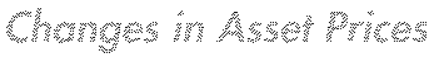

To some extent, the changes in the distribution of household wealth may be attributable to changes in asset prices. Even if each household held exactly the same assets in 1989 and 1983, the distribution of wealth would have changed. Wolff (1994) suggests that such changes may have contributed significantly to the increase in inequality that he measures. He notes specifically that stock prices increased more than house prices, and stock ownership is more concentrated among high-wealth households.

Table 3 reports commonly used price indices for almost all of the asset categories included in the SCF. Indices are not available for unincorporated businesses, but the change in their value may be approximated by the Russell 2000 and Nasdaq small-stock indices.

It is possible to measure the effect of these changes in asset values on the distribution of wealth by applying the indices to the 1983 holdings of each household. In behavioral terms, it is assumed that the household holds the same portfolio in both years, neither buying nor selling any assets, nor for that matter moving.

For most assets, the index can be simply multiplied by the reported 1983 value. In the case of owner-occupied housing, the change in the price of the house is not the change in home equity, for two reasons. First, for households with mortgages, home equity increases in percentage terms by more than the increase in the price of the home. The mean ratio of outstanding mortgage principal balance to house value was 23 percent in the 1983 SCF, and the mean equity was therefore 77 percent of house value. The full value of the increase in house value raises the owner's equity, so the mean home equity increased by 35 percent (27/77) instead of 27 percent. Second, it is assumed that the household continued to make mortgage payments during the six years; otherwise, it would default on the mortgage and lose the house, and thus change its portfolio. The mean remaining life of first mortgages was 15 years, eight months, in 1983; for second mortgages, it was seven year's, 10 months. If homeowners continued to make mortgage payments for the six years between the two surveys, then on average they paid off a non-negligible share of the first mortgage and almost all the second (unless it was a balloon mortgage). The mean reduction in the outstanding principal balance was 24 percent, and the mean increase in home equity was 7.1 percent. The net effect of all 
the assumptions is to raise mean home equity by 42 percent.

In Table 4, the effect of these changes on the Gini coefficient is shown for several individual assets and combinations of assets. The wealth measure used in these calculations is unadjusted and includes automobiles.

The results suggest that changes in asset values as a whole had little effect on the distribution of wealth. The effect of changes for some individual asset categories were large. In three cases-stocks, unincorporated businesses (measured by the Russell Index) and owner-occupied housing-the coefficients change by more than the 1983 standard error, and are about as large or larger as the increase between 1983 and 1989. But the changes go in both directions and largely cancel each other. The changes in stock prices and unincorporated businesses both raise the Gini coefficient, but the change in home equity lowers it, and has about twice the effect of either. Even though stock prices rose more than any other asset and stock holdings are concentrated among richer households, the rise in house prices increased the wealth of a broad range of middle-class households by enough to make the distribution of wealth more equal. The combined effect of the changes in all assets was to lower the Gini coefficient slightly, by much less than its standard error.

The Gini coefficients were also calculated using the 1983 SRC weight (variable B3019), and the results are basically the same.

As a further check, 1989 was used as the base year for asset holdings, and values were deflated back to 1983. This is also shown in Table 4. The results were consistent with those using 1983 as the base year. The most notable differences are that the effect of deflating stock values from 1989 back to 1983 was much smaller in absolute value, and the effect of deflating equity in owner-occupied housing was much larger, so that the effect of changing all asset values simultaneously is larger in absolute value. The combined effect of all the changes is again in the opposite direction from the change in the Gini coefficient. There is also one qualitative inconsistency: Deflating investment real estate values from 1989 back to 1983 has the "wrong" sign. With 1983 as

\begin{tabular}{|c|c|c|}
\hline \multicolumn{3}{|c|}{$\begin{array}{l}\text { Effect of } 1983-89 \text { Asset Value changes on } \\
1983 \text { Cini Coefficienis } \\
\text { (unadjusted net worth, including mutos) }\end{array}$} \\
\hline \multirow[b]{2}{*}{ Asset } & \multicolumn{2}{|c|}{ Change in Gini Coefficient } \\
\hline & 1983 bose year & 1989 base year \\
\hline Storks & +.01348 & -.00214 \\
\hline Bonds & +.00147 & -.00093 \\
\hline Owner-0rcupied homes & -.02530 & +.04437 \\
\hline Investment real estate & +.00101 & +.00533 \\
\hline Unintorporated besiness & +.01311 & -.01155 \\
\hline Forms & -.00088 & +.00036 \\
\hline All ossees combined & -.00240 & +.04536 \\
\hline Net wartll (from Table 2) & +.01497 & -.01497 \\
\hline
\end{tabular}

the base year, inflating real estate equity to 1989 has the effect of raising the Gini coeffcient and increasing inequality. But with 1989 as the base year, deflating real estate equity back to 1983 also has the effect of raising the Gini coefficient and increasing inequality, whereas the opposite sign would be expected.

Using either year as the base, changes in asset values do not generate an increase in inequality, because the changes in home equity more than offset the changes in the value of other assets.

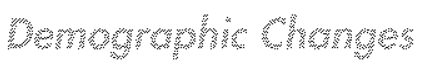

Changes in the composition of the U.S. population may also have contributed to the increasing inequality of the distribution of wealth. Table 5 shows the changes in the SCF sample between 1983 and 1989. The importance of the post-war baby boom can be seen in the age distribution. Almost the only group with a growing share of the population is households with the head age 35 44; these individuals were born in the years from 1939 to 1948 in the 1983 SCF, and from 1945 to 1954 in the $1989 \mathrm{SCF}$. The $5 \mathrm{CF}$ also shows declines in married couples, households with children, and especially married couples with children. There is a reduction in the proportion of adults with less than a high 
school education and corresponding growth in those with at least some college.

In most cases, the weighted percentages in the SCF parallel the percentages in the population, as measured by the Current Population Survey (CPS), conducted annually by the Census Bureau. There are some exceptions. The most important is in the categorization of households by race and ethnicity. The 1983 SCF data report much lower proportions of households in the smaller minority groups than does the CPS. This is apparently because race and ethnicity were determined in 1983 by the interviewer for the SCF, while in the CPS the respondent was asked to identify himself or herself. In 1989, both the SCF and CPS used the self-identification method, which is more commonly used. The CPS reports that persons of Hispanic origin amounted to 7.2 percent of all U.S. residents, compared to only 3.7 percent in the 1983 SCF. Asian and Pacific Islanders were about 1.6 percent of the population in 1983 , and American Indians and Alaska natives were 0.6 percent, while the SCF reports 1.1 percent for both groups combined. The CPS and SCF are much closer in 1989: 8.8 percent in the CPS versus 7.7 percent in the SCF for the Hispanic origin population, and 3.7 percent in the CPS versus 4.3 percent in the SCF for other races. ${ }^{13}$ There are also other differences in the age distribution and household composition, which will be discussed later.

It is possible to get an idea of the importance of these demographic changes on the distribution of wealth by changing the weights for each category of household, substituting the 1989 proportions for each group within the category for the 1983 proportions. This procedure represents the effect of changes for individual households in some cases, such as age and household composition. People tend to add to their wealth as they age, and changes in household status, such as marriage, divorce or the death of a spouse may directly affect

${ }^{13}$ Asicin and Parific Isiander, and Amsorican Iratian ond hassken netive. fre reported as two sepante crife-

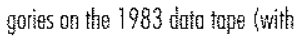
37 ond nime abservations, regpectively and cortitined into a single tategry in 1989 the household's wealth. In others it may not. Individuals do not automatically increase their wealth by completing another level of schooling, for example, although college graduates in general are richer than high school graduates. An adult who completes additional schooling is likely to benefit in the first instance through an increase in income, and then only gradually through an increase in wealth. For the United States as a whole, the effect of educational changes on the accumulation and distribution of wealth will also be felt gradually: New households formed by young adults with more schooling gradually supplant older households whose heads have less, and immigrants with relatively little education arrive in the country. Nor does the overall change in the racial and ethnic composition in the survey correspond to the experience of individual households.

Table 5 also shows the mean wealth for each group in the 1983 survey. The data in the table suggest that the change in the age distribution should reduce the degree of inequality, since the age group closest to the overall mean is almost the only group comprising a larger share of the population in 1989, while groups with higher and lower wealth declined in importance. Conversely, there was a decline in the importance of the household type closest to the mean wealthmarried couples with children-mbut in this case there were also declines in groups with both more and less wealth. All minority groups have mean wealth that is farther from the overall U.S. mean than the large white majority, so the growth of minority households should also increase inequality. In the case of education, the effect is uncertain because low-wealth groups declined in importance and high-wealth groups increased.

As Table 6 shows, most of these demographic changes would have contributed to an increased concentration of wealth, but the effects are small. All are less than the standard error for the 1983 coefficient. The largest effect is from the changing racial and ethric composition of the population, but this is suspect for the reasons discussed. None of the other demographic changes accounted for as much as a quarter of the change in the distribution of wealth. The changing age distribution by itself contributed modestly to a lessening of inequality, and the combined effect of age and household composition changes also reduced inequality.

The same tests for consistency were conducted for the demographic changes as for the changes in asset values, with similar 
results. When the Gini coefficients were calculated with the 1983 SRC weight, the magnitudes and patterns of changes were basically the same. When 1989 was used as the base year, substituting the demographic characteristics for 1983, there were some differences, as can be seen in Table 6. The change in household composition has a positive effect instead of the expected negative one, and the change in the age distribution has a much larger effect when 1989 is used as the base year.

These results may derive from differences between the surveys. For both characteristics, the sample size in one category is much smaller in 1989 than in 1983, and the weighted proportion of the population in that category is larger in the SCF than the CPS in 1983, and smaller in 1989. Single males with children is the smallest household composition category. The sample size in 1989 is only 17 , and the weighted share in the SCF is less than half the 1.1 percent reported in the CPS; in 1983, the sample size is 40 and the proportion in the SCF is much closer to the CPS figure of 0.9 percent.

There is also a very large difference between the two surveys in mean wealth for these households; in 1983, they are relatively poor on average and in 1989 they are above the mean for all households, with mean wealth almost three times as large as in 1983 . The difference in sample size suggests that the 1983 figure is likely to be more accurate. Similarly, "household head under 25" is the smallest age category, and also the poorest. The sample size is only 94 in 1989 , and the weighted share in the $\mathrm{SCF}$ is somewhat smaller than the 5.5 percent reported in the CPS, while in 1983 the sample size is 295 and the proportion in the SCF is larger than the 6.8 percent in the CPS.

These differences suggest caution in interpreting the results in Table 6 . To investigate their importance, weights were changed on the basis of each characterisic separately to match the 1983 and 1989 CPS for age and household composition, and the 1980 and 1990 decomial censuses for race and ehnicity. The inconsistencies in Table 6 did not appear, and the Gini coefficients were generally close to those reported in the top row of Table 2.

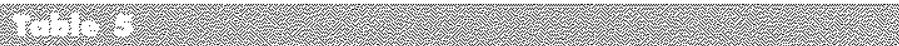 \\ Demographic Composition of SCF, 1983 and 1989}

\begin{tabular}{|c|c|c|c|c|}
\hline \multirow[b]{2}{*}{ Cofegory: } & \multicolumn{2}{|c|}{$\begin{array}{l}\text { Mean Wealth } \\
\text { S1, } 1000 \text { of of } 1989 \text { dotters })\end{array}$} & \multicolumn{2}{|c|}{ Percent of Sample: } \\
\hline & 1983 & 1989 & 1983 & 1989 \\
\hline \multicolumn{5}{|c|}{ Age of household head: } \\
\hline Unter 25 & $\$ 15.3$ & $\$ 13.5$ & 8.0 & 4.8 \\
\hline 2534 & 47.1 & 73.2 & 22.6 & 20.9 \\
\hline 35.44 & 117.9 & 149.7 & 19.5 & 23.3 \\
\hline 454 & 220.9 & 284.1 & 15.5 & 14.2 \\
\hline 5564 & 245.5 & 2659 & 15.0 & 14.5 \\
\hline 6574 & 273.3 & 254.8 & 122 & 13.1 \\
\hline $75+$ & 163.2 & 194.8 & 7.2 & 9.2 \\
\hline
\end{tabular}

\section{Household composition \\ Morried couple, no childen \\ Married couple, thildren \\ Single mele, no chllden \\ Single nule, elituden \\ Singlo femole, no thiforem \\ Single fentele dildren}

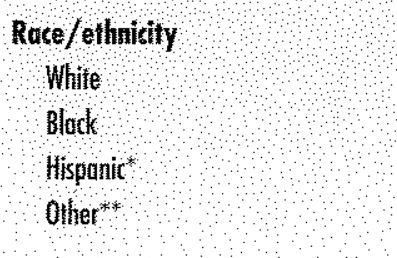

$\begin{array}{rrrr}\$ 271.9 & \$ 305.6 & 29.4 & 29.8 \\ 132.1 & 175.1 & 31.2 & 28.6 \\ 91.8 & 124.2 & 12.0 & 12.8 \\ 61.4 & 167.9 & 1.1 & 0.4 \\ 93.6 & 95.7 & 18.1 & 21.8 \\ 36.2 & 32.2 & 8.2 & 6.7\end{array}$

\section{Educational ot anment \\ Grade school on less \\ Some tiqh stigol \\ High schol graduate \\ Some rollege \\ College graduote or there}

$\begin{array}{rrrr}\$ 175.1 & \$ 216.4 & 82.3 & 75.4 \\ 35.9 & 48.6 & 12.9 & 12.6 \\ 31.9 & 49.2 & 3.7 & 7.7 \\ 88.6 & 176.8 & 1.1 & 4.3\end{array}$

Wean wedih hor an householihs:

150.9

180.7
Alternative weights might be constructed from the CPS, as a more extensive consistency check, but the CPS does not publish crosstabulations in suffient detail and does not use the two smallest racial categories as controls.

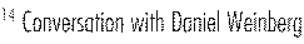
of the Cersus horeat 


\begin{tabular}{|c|c|c|}
\hline \multicolumn{3}{|c|}{$\begin{array}{l}\text { Effect of 1983-89 Demographic Changes } \\
\text { on } 1983 \text { Gini Coefficients } \\
\text { (unadiusted net worth, including autos) }\end{array}$} \\
\hline \multirow{2}{*}{$\begin{array}{l}\text { Demographis } \\
\text { Cotegory }\end{array}$} & \multicolumn{2}{|c|}{ Change in Gini Coefficient } \\
\hline & 1983 base year & 1989 base year \\
\hline Age of hiousehold heod & -.00292 & +.00841 \\
\hline Household composition & +.00148 & +.00267 \\
\hline Combined &,- 00452 & +.01392 \\
\hline Roce/elhnicity of heod & +.00625 & -00770 \\
\hline All three combined & +.00257 & +00479 \\
\hline Eductilion of hend & +00259 & -.00047 \\
\hline Ner worth ffron Fable 2) & +01497 & -.01497 \\
\hline
\end{tabular}

The limitations should not obscure the basic conclusion. None of the results, using either year as the base or any set of weighis, suggest that demographic changes contributed to the change in the distribution of wealth (with the dubious exception of the racial and ethnic changes). All but one of the separate and combined effects of age and household composition are in the direction of making the distribution of wealth more equal, and the effect of education changes is small.

\section{Theone and Weoth}

Both income and wealth Con most comparisons) were more unequally distributed in 1989 than in 1983. Indeed, as reported in the SCF, there was a greater increase in income inequality. The Gini coefficient for income rose more than the coefficient for wealth by any comparison in Table?

The association of these increases suggests that the changes in the distribution of wealth and income may have affected each other, and it is easy to jump to the conclusion that the increase in income inequality caused the increase in wealth inequality, or vice versa.

13 Weicher (1989) grulyzzes the retr. tionship between weolth and age, and the retotionstia between irrores and weatth aromath the eforety for the $1977 \mathrm{SC}$ and the $19835 \mathrm{LE}$ In fact, the relationship between wealth and income is complicated both theoretically and empirically. Part of a household's curren! income is derived from the assets reported in the SCF, especially for the richest households, and at the same time part of the household's current income may be saved and add to wealth in the future. CPS data show that the distribution of income became slightly more unequal from year to year between 1983 and 1989 , while mean and median household income were rising, which might enable the richer houscholds to add relatively more to their assets. The interrelationships cannot be addressed systematically in this article. Nonetheless, it is interesting to look at how the relationship changed between 1983 and 1989.

There are several reasons why income and wealth might not be highly correlated in the SCF. The income reported in the survey is current income, which is not necessarily the household's normal or permanent income. Illness, windfalls and many other circumstances may cause the household's income in a given year to depart from its usual level. Wealth, which is in part the accumulated savings from past income, is likely to be more highly correlated with permanent income than current income. The relationship between current income and wealth is also affected by the age of the adults in the household. Older individuals have higher wealth for given income levels than younger ones, both because they have had more time to accumulate wealth and because, once they retire, their current income is low relative to their past income. Conversely, young adults typically have little wealth relative to their income..$^{15}$

Despite these caveats, the relationship between income and wealth is strong. In Table 7 , household wealth has been regressed on income and the square of income for both years. The coefficients of determination are quite high. The relationship between income and wealth was stronger in 1983 than in 1989 , however, and also more elastic: The intercept is lower in 1983 and the coefficient of income is larger. (The coefficient of income squared is significant in both regressions but its magnitude is too small to generate a measurable departure from a simple linear relationship.)

The two regression lines cross at an income of about $\$ 33,800$ (measured in 1989 dollars). This is the income level at which wealth is the same in the two years. The median household income was $\$ 24,300$ in 1983 and $\$ 25,000$ in 1989 (both also measured 
in 1989 dollars). Thus, upper-income households were not as wealthy at any given income level in 1989 as they were in 1983 , while those at middle- and lower-income levels were wealthier in the later year. This is surprising, since the change in the age distribution shown in Table 5 might suggest that wealth would be higher for households at any given income level in 1989.

It is worth noting that the change in the income distribution reported in the SCF is substantially greater than the change reported in the CPS, which has a much larger sample of about 57,000 households. Between 1983 and 1989, the Gini coefficient in the CPS rose by 0.017 , from 0.414 to 0.431 . This is less than the increase for three of the four SCF comparisons in Table 2. The comparison for which the changes in the SCF and CPS are closest is also the comparison showing a very slight decrease in wealth inequality.

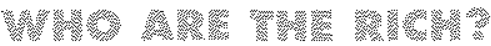

This section adopts a different focus on the distribution of wealth. Instead of looking at inequality across all households, it looks at the holdings and characteristics of the richest 1 percent of households (a group that has attracted interest among other analysts). The purpose is to see if the same households were rich in both years. Attitudes toward an increase in inequality may be different if the absolute level of wealth and the relative position within the distribution change frequently for individual households, especially if this occurs at the upper tail of the distribution.

The SCF has been designed in part to answer the question of how individual households have fared over time, by re-interviewing some of the same households in 1986 and 1989 who were interviewed in 1983. Unfortunately, it is impossible to track any individual households longitudinally because the information about re-interviewing has been suppressed in the 1989 public-use data tape. Nonetheless, it is still possible to analyze the position of the same types of households over time. The threshold for inclusion in this group is $\$ 1.71$ million in net worth in 1983 and $\$ 1.97$ million in 1989.

\begin{tabular}{|c|c|c|}
\hline \multicolumn{3}{|c|}{$\begin{array}{l}\text { The Relationship Between Wealth and } \\
\text { Income, } 1983 \text { and } 1989 \\
\text { (net worth including autos, adjusted for assels; } \\
1989 \text { dollars) }\end{array}$} \\
\hline Variable & 1983 & 1989 \\
\hline Intercept & $\begin{array}{r}-177,338 \\
\quad(10.9)\end{array}$ & $\begin{array}{r}-37,026 \\
(1,6)\end{array}$ \\
\hline Inome & $\begin{array}{r}10.84 \\
(32.8)\end{array}$ & $\begin{array}{r}6.70 \\
(30.2)\end{array}$ \\
\hline Income & $\begin{array}{l}53.3 \mathrm{E}-8 \\
(4.0)\end{array}$ & $\begin{array}{l}-6.41-8 \\
(23.4)\end{array}$ \\
\hline R-squared & .396 & .231 \\
\hline
\end{tabular}

Note: Numbers in parentheses under the coefficients are t-ratios.

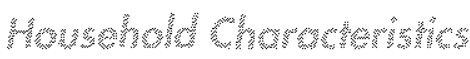

Table 8 shows the demographic characteristics of these rich households. Nearly all were white and nearly all were married couples, although the proportion who were members of minority groups rose from less than 1 percent to more than 5 percent, and the proportion who were not married rose from 10 percent to 16 percent. A substantial majority were college graduates. About three-quarters had no children, or at least none living at home. The median age of the household head was 58 in both years, but in 1989 there were more relatively young households among the rich (17 percent compared to 10 percent in 1983), and fewer in the 55-64 age bracket. A more detailed classification (not reported in the table) shows that about half the households in the 45-54 age bracket had children in 1983, but few households did at older ages. This suggests that by about age 50 , the children of these families have grown up and left home.

Comparison with Table 5 shows that these households are much better educated and quite a bit older than the general population, and are disproportionately white. They are more likely to be married but, perhaps because of their age, less likely to have children living at home. However, the precision of the percentages in Table 8 should not be overemphasized. The number of observations in the top 1 percent of each survey is 


\section{BeVIEW}

JAWUARY/FEBRUARY 1995

\section{2.}

Demographics of the Richest 1 Percent of U.S. Households, 1983 and 1989

\begin{tabular}{|c|c|c|}
\hline & 1983 & 1989 \\
\hline \multicolumn{3}{|l|}{ Age of household heod: } \\
\hline Unider 25 & $0.0 \%$ & $0.0 \%$ \\
\hline $25-34$ & 2.1 & 1.3 \\
\hline 3544 & 8.4 & 15.5 \\
\hline 45-54 & 27.9 & 27.0 \\
\hline $55-64$ & 30.3 & 22.2 \\
\hline $.65-74$ & 20.9 & 22.1 \\
\hline $75+4$ & 10.4 & 11.9 \\
\hline \multicolumn{3}{|l|}{ Household composition: } \\
\hline Married couple, no children & $66.2 \%$ & $58.5 \%$ \\
\hline Married couple, children & 23.3 & 25.1 \\
\hline Single mole, no trildren & 4.0 & 9.5 \\
\hline Single mole, cilldren & 0.1 & 26 \\
\hline Single femole, no trildren & 6.4 & 37 \\
\hline Single female, childsen & 0.0 & 0.7 \\
\hline \multicolumn{3}{|c|}{ Race/ethnicity of household head: } \\
\hline White & $99.2 \%$ & $94.5 \%$ \\
\hline Black: & 0.1 & 0.7 \\
\hline Hisponic & 0.0 & 1.1 \\
\hline Oiher: & 0.7 & 3.7 \\
\hline \multicolumn{3}{|l|}{ Education of household head: } \\
\hline Grade school & $1.3 \%$ & $2.8 \%$ \\
\hline Some highlischool & 1.5 & 1.3 \\
\hline High sthoolghuduale & 14.1 & 8.8 \\
\hline Some college & 20.3 & 14.0 \\
\hline college graduate er more & 62.8 & 73.2 \\
\hline
\end{tabular}

if What $(1994)$ stows that o luge shore of weolth of the top ontehtudf of 1 percent (which te tormes tha "supertichen") in 7989 consisted of unithesporated businesses and investment real estigte, and he spectulates that this wos the ouentse to weath in the 1980s. The toto in todes 8 and 9 only grity sup port this inferente. Unincoponted busipesces were a latger share of that total net woth of the richest $]$ percent, but were the nost impor tani osset in the puttolio for fewer of theตา. not large to begin with: 287 in 1983 and 456 in 1989. Thus, there are not likely to be many in some of the smaller demographic categories. Where the surveys have marked differences in the samples and weighted proportions for the smaller categories, as shown in Table 5 and discussed in the previous section, the representation of these categories among the top 1 percent is likely to vary as well, and the proportions in these categories in Table 8 may be suspect. The figure for minority groups in 1983 is especially suspect because of their underrepresentation in that year's $\mathrm{SCF}$, as discussed earlier.

\section{Assets Held by when}

Table 9 describes the components of net worth for these households. As the top panel shows, in both years unincorporated businesses constituted the largest share of their wealth, over one-third in 1983 and almost 40 percent in 1989. Commercial and rental property accounted for about one-sixth in both years. The most surprising finding is the sharp decline in the importance of stock ownership, despite the stock market boom of the 1980s.

These patterns vary by age. In general, stocks are more important and unincorporated businesses are less important for older households. In 1983, for households under 65, unincorporated businesses were the largest component of net worth; for those 65 or over, stocks were. In 1989, stocks were the largest holding only for those 75 or over. At the other end of the age distribution, if young households did manage to qualify for inclusion among the very rich, they did it as owners of unincorporated businesses or perhaps, in 1983 , as real estate investors.

The second panel shows the importance of the different assets to individual households: What was the most important asset in the portfolio of each rich household? Unincorporated businesses were the most important by this measure also in both years, although the proportion declined from 42 to 34 percent. Investment real estate was the most important asset for about one-fifth of the richest households in both years. Stocks declined by this measure as well. ${ }^{15}$

The marked increase in the importance of miscellaneous assets (collectibles, debts owed to the household, oil and gas leases) in both panels may result from a change in the questionnaire. Nine more categories were listed separately in 1989, including future proceeds from a lawsuit or an estate, royalties, deferred compensation, futures contracts, non-publicly traded stock, and cash not elsewhere classified. At the same time, however, the most frequently cited miscelianeous asset in 1983 -boats - was moved to the "vehicle" category in 1989 , along with campers, airplanes and motorcycles.

Three times as many households reported owning miscellaneous assets in 1989 as in 
1983 among the population as a whole, and this is reflected among the richest households as well. Miscellaneous assets were the most important asset for a remarkably large number of wealthy households in 1989. Mean holdings of miscellaneous assets for wealthy households reporting such assets increased from $\$ 148,000$ in 1983 to $\$ 546,000$ in 1989 (both measured in 1989 dollars). Not many wealthy households reported holding assets in the categories added in 1989 , but those who did typically reported holdings of $\$ 250,000$ or more. In addition, a category of "other" was available in 1989, besides the 29 specified, and one household reported $\$ 28$ million worth of such "other" miscellaneous assets.

Given the importance of unincorporated businesses among the richest households, it is worth taking a brief look at the kinds of businesses they own. The SCF asks what the business does, for those in which the household has a management interest. In 1983, the most common classification was "professional practice," an unfortunately broad category including law, medicine, accounting and architecture specifically, and perhaps others as well. Some 22 percent of the richest. households owning unincorporated businesses were in this category. The second most common classification, at 20 percent, was "other wholesale/retail outlets," including everything except food and liquor, restaurants, gas stations and direct sales. In 1989, real estate/ insurance was much the most common, at 43 percent, but few of the tichest households were in these lines of business in 1983. "Other outlets" was the second most common classification, at 26 percent. In general, there is not much correspondence among the kinds of businesses owned between the two years, except in the broadest classifications.

Respondents were asked about the value of two actively managed businesses in 1983 and three in 1989, along with summary questions about other actively managed businesses in both years. Also in 1983, households in the high-income sample were not surveyed unless they volunteered to participate, while in 1989 they were surveyed unless they declined to participate. These differences may limit the comparability of the richest households between the surveys.

\section{0}

\section{Asset Holdings of the Richest 1 Percent of Households, 1983 and 1989}

\begin{tabular}{|c|c|c|}
\hline \multicolumn{3}{|c|}{ Relative Importance of Individual Asset Categories } \\
\hline & 1983 & 1989 \\
\hline Unincorporated business & $33.8 \%$ & $39.7 \%$ \\
\hline Stodks: & 18.2 & 7.7 \\
\hline Investment real estate & 16.7 & 16.5 \\
\hline Hone equity & 8.7 & 8.2 \\
\hline Trusts: & 6.4 & 3.8 \\
\hline Bonds & 5.9 & 5.7 \\
\hline Farms: & 2.7 & 2.6 \\
\hline Miscelloneous ossets & 1.0 & 5.9 \\
\hline All other & 6.0 & 9.9 \\
\hline
\end{tabular}

\begin{tabular}{|c|c|c|}
\hline & 1983 & 1989 \\
\hline Uninconporated business & $41.8 \%$ & $33.7 \%$ \\
\hline Investment real estufe & 20.5 & 22.2 \\
\hline Stocks & 16.3 & 9.0 \\
\hline forms & 7.0 & 3.1 \\
\hline Tusts & 4.9 & 7.4 \\
\hline Bands: & 4.5 & 3.6 \\
\hline Miscellaneous & 0.3 & 8.9 \\
\hline All oher & 4.7 & 12.1 \\
\hline
\end{tabular}

Taken at face value, the data on unincorporated business suggest that different households were in the top 1 percent in both years. The shifts in portfolio composition support the same inference.

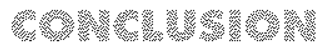

The distribution of wealth probably became slightly more unequal between 1983 and 1989 , but this conclusion does not hold for all specifications analyzed in this article. The sign and magnitude of the change depend on how broadly wealth is defined, and on such technical issues as what weights are used and whether and how the data for individual households are adjusted on the basis of national balance sheet data.

No single explanation appears to account for most, or very much, of the change in the distribution of wealth. Neither changes in 
asset values or broad demographic changes are very important. The high correlation between current income and wealth suggests that the change in the distribution of wealth may mirror the change in the distribution of income, but the relationship between income and wealth became less pronounced over the period.

The analysis in this article can best be described as a preliminary exploration of the wealth data in the SCF, and it has considered fairly simple explanations of the change in the distribution. A number of more specific and sophisticated issues may merit further analysis, based on the work to date:

(1) It is possible to look more closely at the effect of changes in household composition, particularly divorce and remarriage, since changes in marital status between 1983 and 1989 are reported for individual respondents in the $1989 \mathrm{SCF}$.

(2) The growing employment opportunities for women suggest that it would be worthwhile to analyze the effect of the labor force status of both members of married couples. Two-earner, two-professional couples (doctors married to doctors or to lawyers, for example) appear to be growing in importance; these may be high-wealth households. More generally, the contribution of a second earner to household wealth can be studied in the SCF.

(3) The $1983 \mathrm{SCF}$ illustrates the importance of pensions and Social Security in the portfolios, broadly defined, of households with relatively low net worth. It may be possible to extend these calculations to 1989 , to investigate whether inequality is rising when they are included and whether lower-wealth households are substituting them for other types of assers.

Finally, it may be that the increase in inequality is a cyclical phenomenon. As noted at the beginning of this article, the years from 1983 to 1989 comprise most of a long economic expansion. The Census Bureau reports that the distribution of income tends to become more unequal during expansions. Gini coefficients for household income have risen in every year since 1968, except three: 1974, 1980 and 1990 , all of them years of recession. Over the 1968-92 period, the Gini coefficient rose from 0.388 to 0.433 , or slightly less than
0.02 per year. During the 1983-89 expansion, it rose from 0.414 to 0.431 , or about 0.024 per year. There are so few surveys with data on household asset holdings that it is difficult to consider the distribution of wealth cyclically, but the 1992 SCF may shed light on this conjecture, since it covers the downtum of 1990-91.

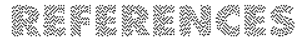

Anteniewicz, Rochelle. "A Comperison of the Howsehold Serter from the Flow of Funds Accounts and the Survey of Consumer Finences," unpebilished puper (ntwember 1994).

Avery, Robert B. "Comment," in Robert E. Lipsey and Helen Stone lice, eds., The Measurement of Soving, Invesfment and Wodth. University of Chictgo Press, 1989, pp. 839-44.

and Gregery E. Elliehousen. "Financid Choncteistics of

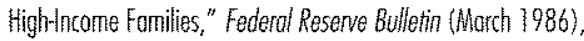
pp. $163-177$.

and 1983 Sunvey of Consumer Finonces: Technicd Monul and Codebook. Bourd of Govenos of the Federol Reserve System, Apill 1985 (Lost Revision: Febuory 15, 1990 ).

and Arther B. Rennickell. "Measuing Wealth with Sunvey Doto: An Evaluation of the 1983 Suney of Consumer Finatces," Review of income and Weoth (December 1988), p. $3396 \%$.

Glem B. Canner, and Thames A. Gustofson. "Survey of Consumed Finances, 1983," Federol Resenve Bulle in (Septemieg 1984), pp. 679-92

Consumer Finances, 1983 : A Second Repon," Federd Resenve Bulletin (December 1984), pp. 857-68.

Curtin, Richurd F, E. Thomes Juster, and Jomes N. Moggan. "Survey Estimetes of Wealth: An Assessment of Qudily," in Robent E. Lipsey and Helen Stone The, eds., The Measurement of Saving, Investment, and Wenth. University of Chicgo Press, 1989 ap. 473548.

Efron, Btadley, and R. I. Tibshirani. An Introduction to the Bootstrop. Chammatand Hall, 1993.

Kennickell, Athur, and tanice Shuck-tharquez. "Changes in Fomily Finonces from 1983 to 1989: Evidence from the Survey of Consumer Finonces," Faderd Resenve Bulfetin (Jontory 1992), pp. 1.18.

and Harthe Ston-Mcluer. "Changes in Family Finances from 1989 to 1992: Evidence from the Sarvey of Consumes Finances," Federol Resewe Bulletin (October 1994), ap. 861-82.

and R. Louise Woodburn. "Estimation of Househald Net Worth Esing Model-Based and Designtased Weights: Evidence fon the 1989 Survey of Consumes Finonces," unpublished poper, Federol Resenve Boad, April 1992. 
Lemon, Roberf I., and Sllono Yitehaki. "Inpowing the Acuray of Estimates of Gin Coefficients," Jound of Economatrics (September 1989). .9. $43-7$.

Worgan, James 1 . "The Anatony of Income Distribution," Review of Economics and Stotistics (Angust 1962), po. 270-83.

Muth, Richard F. "The Dentand for Nonfarm Housing," in Arnold C. Hotberger, ed. the Demond for Durable Goods. University of chicago Press, 1960, pa. 29.96.

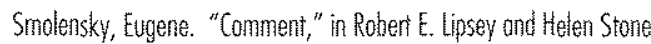
Tice, eds., The Measurement of Soving, Investment, and Weath. Universiy of Chicogo Press, 1989, pp. 548-51.

U.S. Busean of the Censur. Stotistical Abstruc of the United States (vorious years). (vorious years) Price Index of New One-Family Homes Sold, Series (2)

"Trends in the lnome of Fonities and Persons in the United States 1947 to 1964 , "Techical Poper No. 17 (Augusi 1967).
"Money Income of Households, tamiles, and Persons in the United Stutes: 1967-1992, "Curent Population Repots, Series P60-184 (Sentember 1993).

Weicher, Jahn C. "Wentiti and Poverty Among the Eldeaty," in Marion Ein Lewin and Sean Sullwon, eds. The Care of Tomornow's Ederly. Americon Enterprise insituste, 1989, pa. 17-27.

White, Lawrence I. The S\&L Debode. Oxford University Press, 1991.

Wolf, Edward H. "Estinntes of Household Wedth mequality in the U.S. 1962-1983," Review of home ond Weoth (Septernter $1987\rangle$, pp. 237.56

"Trends in Househodd Wealth in the United States, 1962-83 and 1983-89," Review of Income and Wealth (June 1994), po. 14374 .

Yitzhaki, Shomo. "Colaloting Jocknife Voriance Estimators for Parameters of the Giri Methad, "Joumal of Businass \& Economic Stotistics (Aptil 1991), pp. 235-39. 